\title{
Hédi Bouraoui, Paris berbère
}

\section{Nicola D’ambrosio}

\section{(2) OpenEdition}

\section{Journals}

\section{Édition électronique}

URL : http://journals.openedition.org/studifrancesi/3899

DOI : 10.4000/studifrancesi.3899

ISSN : 2427-5856

\section{Éditeur}

Rosenberg \& Sellier

\section{Édition imprimée}

Date de publication : 1 décembre 2012

Pagination : 620-621

ISSN : 0039-2944

\section{Référence électronique}

Nicola D'ambrosio, « Hédi Bouraoui, Paris berbère », Studi Francesi [En ligne], 168 (LVI | III) | 2012, mis en ligne le 30 novembre 2015, consulté le 07 mars 2021. URL : http://journals.openedition.org/ studifrancesi/3899; DOI : https://doi.org/10.4000/studifrancesi.3899

Ce document a été généré automatiquement le 7 mars 2021.

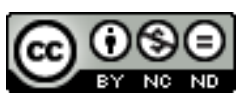

Studi Francesi è distribuita con Licenza Creative Commons Attribuzione - Non commerciale - Non opere derivate 4.0 Internazionale. 


\title{
Hédi Bouraoui, Paris berbère
}

\author{
Nicola D'ambrosio
}

\section{RÉFÉRENCE}

HÉDI BOURAOUI, Paris berbère, Ottawa, Les Éditions du Vermillon, 2011, pp. 294.

1 Après sa trilogie sur la Méditerranée, Cap Nord, Les aléas d'une odyssée, Méditerranée à voile toute, Éditions du Vermillon (Ottawa), Hédi Bouraoui vient de publier un roman qui n'en finit pas de nous étonner par la richesse et la modernité des thèmes traités et par une langue claire comme l'eau de roche. Dommage que la France ne reconnaisse pas dans toute sa valeur la perspicacité d'un intellectuel et le génie littéraire d'un poète et d'un romancier qui a certainement contribué au rayonnement de la langue et de la culture françaises dans le monde entier.

Retrouver la mère... Sauver l'honneur du père, voilà les deux centres d'action de ce roman bouraouien. Si Théo court à la recherche de sa mère naturelle qu'il n'a jamais connue, Tassadit, une jeune algérienne qui deviendra sa femme, veut à tout prix venger l'honneur du père, un Harki, qui, rentré en France, a été mutilé par vengeance. Hédi Bouraoui reconstruit d'une façon impeccable le milieu où évolue une famille bourgeoise aisée, dans une petite ville française, Clairac, qui donne beaucoup d'importance aux conventions sociales et qui veut à tout prix sauver les apparences. Elle va se révéler gâtée et pourrie jusqu'à la moelle. «J'étais mal à l'aise dans ma peau» dira Théo, ce jeune homme qui évolue dans ce milieu-là et qui organise, à la maison, des surprisesparties, des surboums avec ses ami(e)s du lycée, dans une intimité totale.

3 L'ironie bouraouienne est corrosive lorsque l'auteur nous décrit les aventures amoureuses de Théo avec Odette, la serveuse de la cantine de son lycée, qui loue une chambre d'hôtel à Lourdes, la ville de Bernadette Soubirous, où elle fait son pèlerinage annuel, et passe d'une petite prière à ses ébats amoureux ou lorsqu'il nous présente le père Alcide qui s'assombrit parce qu'il perd Ariane, sa fille adorée, qu'il considérait comme sa belle-fille et qu'il avait violée plusieurs fois pour se venger de la prétendue trahison de sa femme. Sans parler de l'humour cinglant dans la scène où le prêtre, 
devant le cercueil du père Alcide, parle de lui comme d'un «mari fidèle, père exemplaire». En profitant de ses études à Paris, Théo va se détacher de son père, un ancien militaire qui a choisi de devenir directeur d'un petit Collège de province, pour exercer son autorité, parce que sa mission consiste à «serrer les écrous dans un monde permissif qui fout le camp de partout». Un vrai hypocrite, un homme rompu à la vie libertine qui, tout en faisant attention aux apparences, a de nombreuses liaisons dangereuses qui sont la prérogative des riches, paraitt-il, qui peuvent tranquillement enfreindre la morale.

Bouraoui trace avec délicatesse le portrait d'Alfred, l'oncle de Théo, un homme simple, un vigneron, le seul capable de dialoguer avec lui d'une manière franche, et de lui manifester son amour, qui sera partagé. C'est lui qui va rencontrer son neveu à Paris, après son emprisonnement, et qui va lui conseiller de travailler fort pour devenir quelqu'un. Avec quelques touches, le pinceau d'Hédi Bouraoui brosse le tableau de Mai 68. Une révolution, que tout le monde a essayé de dramatiser: «Terminé le match, on se demande à quoi tout le monde a bien pu jouer. [...] Ce qui m'a passionné... ce fut son côté ludique», déclenchée par la bourgeoisie intellectuelle qui s'ennuie. Aliénée et blasée, elle s'oppose à la société de consommation, à la société féodale et à ses mandarins et aspire au changement pour faire triompher l'imagination. Théo n'est pas un soixante-huitard convaincu, il ne la considère pas comme "sa révolution»; il est plutôt contre les intolérances idéologiques et religieuses. L'expérience de la prison va le pousser à se concentrer sur ses objectifs de carrière, à s'affranchir de l'autorité paternelle, à se révolter contre son père, à ne plus suivre ce faux modèle et surtout à faire le tri de ce qu'il doit jeter ou garder dans sa vie. Profonde métamorphose du personnage qui l'encourage à se mettre sur les traces de sa mère. C'est d'elle que viendra le salut. Jacqueline, l'amie de sa mère, va devenir la complice de Théo. Avec elle il retrouvera la douceur de vivre et apaisera sa blessure dans le jeu de l'amour et de la faisance: «Une vie nouvelle va commencer»: «Repartir à zéro, faire table rase, puis sur ce sol aseptisé bâtir [ma] nouvelle faisance».

Si Théo cherche sa mère, Tassadit veut sauver l'honneur de son père à travers la vengeance. Arezki Ait avait été un militaire indigène d'Algérie, un Harki qui avait servi dans les milices supplétives à côté des Français parce qu'il avait cru à la devise française, Liberté, Egalité, Fraternité, tout en suivant la voix de sa conscience. Mais la France va oublier les Harkis qui se trouveront exposés aux violences de l'O.A.S. et des Algériens qui les considèrent des traîtres à leur patrie, et qui devront subir l'exil, l'aliénation. Par contre, tous les honneurs sont réservés aux Pieds-noirs qui ont toutes sortes de priorité aussi bien pour le logement que pour le travail. Tassadit espère que son mari, Théo, l'aidera à débusquer l'assassin de son père. Pourquoi s'est-elle mariée avec un Roumi si ce n'est dans le but de le venger? Tassadit ne réussira pas à pardonner la trahison de son père Harki et la sienne, à cause de son mariage avec un Français; elle restera prisonnière de sa faute et de son passé et trouvera la paix en se remariant à un cousin kabyle. L'échec d'un couple, ou l'échec d'un couple mixte qui ne réussit pas à harmoniser les différences culturelles - Théo semble ancré au passé et ne vivre qu'«au rythme de ses propres racines» - même si leurs ancêtres, Théophile de Viau, le poète aristocratique, tapageur, ombrageux, tendre et violent et Si Mohand, le poète berbère, ont partagé l'amour de la poésie et le don «du verbe qui enflamme?». Tassadit n'a pas la force de sortir de l'ornière de sa culture d'origine, de survivre hors de sa communauté; elle reste ancrée dans son background social d'origine, n'additionne pas les éléments étrangers à sa propre culture, ne réussit pas à accepter les différentes composantes de 
son identité qui est plurielle et vit le drame de la recherche de son identité, qui devient meurtrière. Elle s'accroche à ses préjugés, à son intégrisme culturel et religieux, trouve au sein de sa communauté les réponses à ses problèmes. Une héroïne négative dans la vision transculturelle bouraouienne parce qu'elle ne va jamais harmoniser ses valeurs avec celles de son pays d'accueil, la France. Elle finit par se découvrir étrangère par rapport à son mari et à leurs enfants: leur fille France se révoltera contre l'acharnement islamique de sa mère et Charlot sera horrifié par les images de son pays d'origine à la dérive.

6 Paris berbère, nous transporte enfin de l'autre côté de l'Atlantique, aux États-Unis, là où Ariane, l'amie de lycée de Théo, une jeune fille attachante, combative, ouverte mais qui joue à l'héroïne romantique, s'est envolée avec son Bob Maraviglia, un Italo-américain qui veut oublier ses origines italiennes et son héritage linguistique et culturel et qui privera ses enfants de points de repères - Bob Junior va se suicider - si fier de l'american way of life, qui n'est qu'un «abrutissement perpétuel au travail». Un pays bigot, plein de contrastes sociaux, où l'on mélange la politique et les love affairs, avec son "gigantisme rabelaisien», une superpuissance qui a subi de grands échecs, comme au Vietnam. Avec ses présidents assassinés, sans oublier des intellectuels comme Martin Luther King et Malcom X, avec le racisme et son «rêve américain» qui d'ailleurs se confond avec la "conquête sur le moi et sur son environnement, à tout prix et par tous les moyens», où fleurit l'une des plus puissantes démocraties. Dans ce roman qui fait la navette entre l'Algérie, la France et les États-Unis, Bouraoui parvient à nous donner une vision d'ensemble époustouflante: si les Français ont eu des génies dans le domaine littéraire et philosophique, des théoriciens imbattables comme Descartes, Condillac, Sartre, cet immense Disneyland qu'est l'Amérique est un laboratoire qui transforme les théories en «praxis rentable».Ce roman traite un sujet tabou en France qui taraude la conscience des Français d'aujourd'hui: «De Gaulle a abandonné les Harkis: c'est son crime - et le nôtre», écrivait Jean Daniel dans son Éditorial («Le Nouvel Observateur», n. 2341, 17-23 septembre 2009), cité par l'auteur, sans oublier le thème éternel de la création littéraire, la «faisance», «cette chose palpitante de vie et qui ne sert à rien... ce coup pour rien, pour le plaisir», qui comble de bonheur, un zeste de poésie, un refuge qui nous protège des difficultés de la vie, un antidote contre la mort intérieure, qui permet de traquer la vérité et de saisir le monde, parfois d'un seul coup de plume. Le lecteur suit les aléas du livre de Théophile de Viau, Les œuvres, un fil d'Ariane dans le labyrinthe romanesque qui contribue au rebondissement de l'action.

7 Paris berbère est un hommage aux écrivains maghrébins du siècle passé: de Feraoun, lâchement assassiné par l'O.A.S, à Kateb Yacine, Taos Amrouche, Malek Haddad, Mustapha Nissaboury, Abou-l-Qasim Ach-Chabbi, Jean Amrouche, Mohammed Dib, Malek Alloula, Albert Memmi, pour finir avec Saint Augustin, Montesquieu, Charles Baudelaire, Pierre Loti, Eugène Fromentin, Frankétienne (Haïti) et des théoriciens comme Jacques Lacan et Julia Kristeva: «J'ai toujours rêvé d'écrire un roman poétique qui ne rebuterait ni les amateurs de poésie pure et dure, ni ceux du roman réaliste traditionnel. Un classicisme de bon aloi, avec un je-ne-sais-quoi qui le sortirait des carcans des formes immuables, de cet attachement du Français aux genres familiers», dit Théo. Je pense que Paris berbère a accompli ce rêve bouraouien. C'est un roman plein d'humour et d'un brio étincelant, un regard perçant sur l'histoire de la fin du siècle dernier et sur les problèmes liés à l'identité et aux dialogues des cultures, un livre qui a atteint le dernier degré d'achèvement dans l'univers scriptural d'Hédi Bouraoui. Si 
Tassadit a perdu son pari, Bouraoui l'a certainement gagné dans le domaine de l'écriture, et les lecteurs avec lui! 